\title{
Dementia in two histologically confirmed cases of multiple sclerosis: one case with isolated dementia and one case associated with psychiatric
} symptoms

\author{
Bertrand Fontaine, Danielle Seilhean, Ayman Tourbah, Catherine Daumas-Duport, \\ Charles Duyckaerts, Nina Benoit, Bertrand Devaux, Jean-Jacques Hauw, \\ Gérald Rancurel, Olivier Lyon-Caen
}

Services de

Neurologie, Hôpital de

la Salpêtrière, 47

boulevard de

l'Hôpital, 75013 Paris,

France

B Fontaine

A Tourbah

N Benoit

G Rancurel

O Lyon-Caen

INSERM U134,

Hôpital de la

Salpêtrière, 47

boulevard de

l'Hôpital, 75013 Paris,

France

B Fontaine

A Tourbah

Laboratoire Raymond Escourolle, Hôpital de

la Salpêtrière, 47

boulevard de

l'Hôpital, 75013 Paris,

France

D Seilhean

C Duyckaerts

J-J Hauw

Anatomie

Pathologique, Centre

Hospitalier Sainte

Anne, 1 rue Cabanis,

75014 Paris, France

C Daumas-Duport

INSERM U360,

Hôpital de la

Salpêtrière, 47

boulevard de

l'Hôpital, 75013 Paris,

France

C Duyckaerts

N Benoit

J-J Hauw

O Lyon-Caen

Service de

Neurochirurgie,

Centre Hospitalier

Sainte Anne, 1 rue

Cabanis, 75014 Paris,

France

B Devaux

Correspondence to:

Professor O Lyon-Caen

Fédération de Neurologie,

Hôpital de la Salpêtrière, 47

boulevard de l'Hôpital,

75013 Paris, France.

Received 18 January 1993

and in final revised form

and in final revised 25 May 1993.

\section{Abstract}

During the past 10 years, considerable attention has been devoted to cognitive impairment in multiple sclerosis. Occasionally this impairment may be so severe that multiple sclerosis presents as a dementia associated with only minor neurological signs and symptoms. The cases of two women affected by multiple sclerosis who presented with a pure dementia are reported. In the first patient, a progressive apragmatic behavioural disturbance with reduced short term memory and learning abilities were the main clinical features. Neuropathological examination of the brain disclosed numerous plaques in the periventricular white matter, with severe atrophy of the corpus callosum. Plaques were also seen in the white matter of both hippocampus and in the columns of the fornix. The impairment of short term memory could be linked to these lesions. Behavioural changes were probably related to the bilateral lesions of the long associative bundles that disconnected the frontal lobes from other parts of the cerebral hemispheres. In the second patient, visual hallucinations were associated with cognitive dysfunction. MRI showed large plaques in the white matter of both left frontal and temporal lobes. Smaller plaques were also present in the periventricular white matter of the occipital lobes, the nature of which were confirmed by a stereotactic biopsy.

\section{(F Neurol Neurosurg Psychiatry 1994;57:353-359)}

Cognitive dysfunction in multiple sclerosis was first recognised with the initial description of the disease, in which Charcot noted a "weakening of memory", "slow conceptual thoughts", and a "blunted affective and intellectual life". It was not until recently, however, that much attention was devoted to this subject. $^{23} \mathrm{~A}$ number of neuropsychological studies reported different proportions of patients with multiple sclerosis who had cognitive abnormalities, ranging from $13 \%$ to $65 \% .{ }^{4}$ The populations under study were not always comparable, and most patients were followed up in university based neurology departments. A recent study that recruited patients from the membership of a local multiple sclerosis society found cognitive dysfunction in about $40 \%$ of patients. ${ }^{5}$ Cognitive disability was first considered to be the hallmark of the later stages of disabling multiple sclerosis. ${ }^{1}$ Several studies reported that significant cognitive abnormalities may also occur in an early stage of the disease in mildly disabled patients, ${ }^{6-8}$ and even at the first attack of the disease. ${ }^{9}$ This may interfere with the patients' social and professional life. ${ }^{10}$

Cerebral demyelination disrupts a wide range of cognitive processes, which may differ from one patient to another, depending on the localisation of the plaques. Task memory is most often impaired in patients with multiple sclerosis. Various patterns have been described, depending on the population and the neuropsychological tests used. ${ }^{4}$ The most common defect is a memory loss, particularly of learning ability, with relative preservation of retention memory. This concerns both verbal and visuospatial material. ${ }^{24}$ Other cognitive dysfunctions have been reported, such as a reduction in verbal fluency and mood changes including both an apathetic and depressed state. ${ }^{24}$

Several findings have shown that cognitive impairment, which presented as isolated dementia or disproportionally severe cognitive dysfunction compared with the other types of disability, may occur in multiple sclerosis. ${ }^{211} 12 \mathrm{We}$ describe two cases with histologically confirmed multiple sclerosis, one with pure dementia and the other with psychiatric symptoms associated with the dementia. We also report the extensive neuropathological examination of the first case.

\section{Case reports}

CASE 1

A 51-year-old right handed woman was referred to hospital in November 1984 because of memory disturbance and behavioural changes. She had been surgically treated for Graves' disease in 1974, and since then had been treated with thyroxine. There was no history of neurological or psychiatric disease in her family. The chronology of the behavioural changes was reconstructed with the help of her husband. Although aware of 

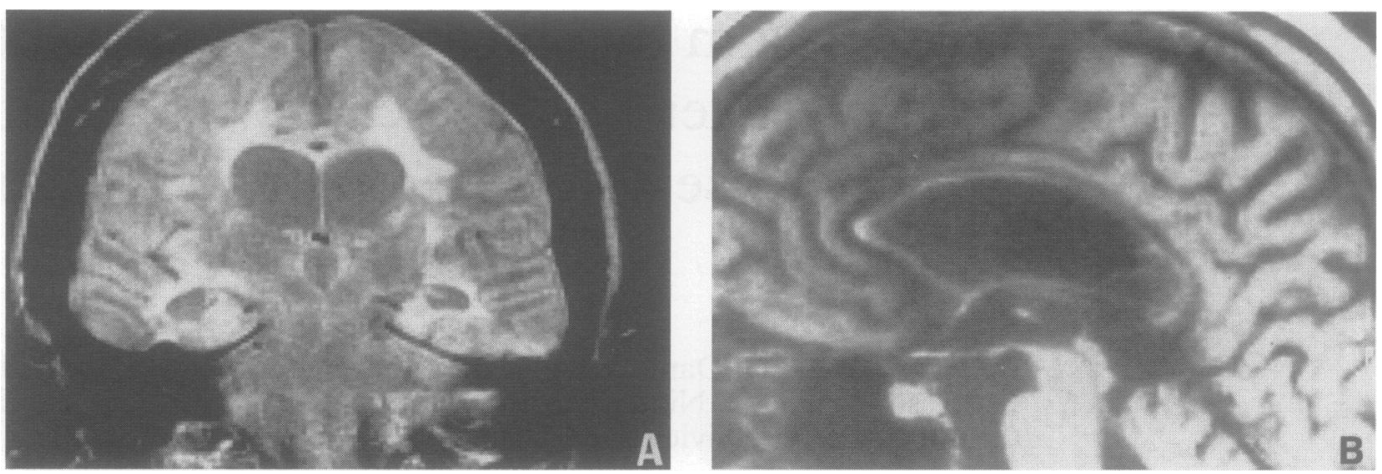

Figure 1 MRI examination of brain of case 1. (A) T2-weighted coronal section through the corpus callosum and the temporal lobes. (B) T1-weighted image of a sagittal section comprising the corpus callosum.

her problems, the patient denied them. Her husband reported that over the past 10 years, but more obviously over the past four or five years, the personality of his wife had changed. She was more aggressive and she displayed emotional lability (non-motivated laughing and tear crises). She gave up her housekeeping activities progressively, and had a lack of libido. She was still playing cards, one of her favourite leisure occupations, but her performance had worsened. The husband decided that she should have a neurological examination when he became aware of her memory loss, which concerned only recent events. Her memory impairment had increased mostly during the past year. A neuropsychological examination was performed in November 1984. The patient was euphoric with a defective memory for recent events and fixation, but normal remote memory. She was able to recall the date, but not the name of the hospital. There was no abnormality of cortical instrumental functions. Psychometric tests showed an IQ of 102 on the Binois-Pichot vocabulary,,$^{13}$ an IQ of 106 on PM 38, ${ }^{14}$ and an MQ of 79 on the Wechsler memory test. ${ }^{14}$ She did not recall the Rey figure after having copied it. ${ }^{14}$

Neurological evaluation was normal: there was no gait disorder and cranial nerves, cerebellar function, and corticospinal and sensory pathways were normal.

Blood tests, which included erythrocyte sedimentation rate, blood cell count, tests for hepatic and renal function, and screening for DNA antibodies were normal. Thyroid function was normal. Tests for thyroid antibodies were negative. An EEG showed a slightly destructured base rhythm with abundant $\delta$ waves predominantly in the left hemisphere. There were no paroxystic or localised abnormalities. The initial cerebral CT November 1984) and the successive examinations with and without contrast enhancement showed a moderate enlargement of the four ventricles and bilateral white matter hypodensity that was localised close to and in contact with the frontal and occipital horns of the lateral ventricles. Examination of CSF gave a protein concentration of $7 \cdot 1 \times 10^{-3} \mathrm{~g} / 1,13 \% \gamma$ globulin with a polyclonal profile, and lymphocytes $1.2 \times 10^{6} / 1$. Visual, somatosensory, and auditory evoked responses were not studied.
Examination by MRI was performed in July 1986 on a 0.5 Tesla machine without injection of gadolinium. T1-weighted sagittal sections showed a pronounced atrophy of the corpus callosum (figs $1 \mathrm{~A}$ and $1 \mathrm{~B}$ ), and small areas of low signal in the subcortical and periventricular white matter, which were predominant around the frontal and occipital horns on transverse sections. On T2weighted sequences, slight cortical atrophy and moderate ventricular enlargment were noted on coronal sections. Large areas of high signal were seen around ventricules, in the subcortical white matter, and in the white matter of the temporal lobes (fig 1A). These areas were asymmetrical and confluent, particularly in the frontal white matter. The cortex, the basal ganglia, and the subtentorial structures were preserved.

The clinical state of the patient progressively deteriorated. A new psychometric evaluation was performed in October 1986. It showed an IQ of 83 on the Binois-Pichot vocabulary, ${ }^{13}$ an IQ of less than 80 on the PM $38,{ }^{14}$ and an MQ of 69 on the Wechsler memory test. ${ }^{14}$ In September 1987, the memory loss for fixation and for recent events had worsened to such an extent that the patient was unable to play cards and could not take any simple decisions on her own at home. A constructive apraxia and an apraxia for dressing were noted. Treatment by infusion of 1.5 $\mathrm{g}$ methylprednisolone had no beneficial effect. The patient died in November 1987.

A postmortem examination was performed 24 hours after death. After removal, the brain and the spinal cord were fixed in $4 \%$ formalin. Coronal sections of the cerebral hemispheres and sections perpendicular to the axis of the brainstem and spinal cord were taken. Representative sections of the hemispheres, brainstem, and spinal cord were either embedded in celloidin and stained with haematoxylin-eosin and the Loyez method for myelin or embedded in paraffin and stained with haematoxylin-eosin, Bodian's protargol coupled with Luxol fast blue, and Congo red. The brain weighed $1100 \mathrm{~g}$. There was mild widening of the lateral fissure and flattening of the gyri in frontal, temporal, and parietal regions. Macroscopic examination of formalin fixed sections showed enlargement of the frontal and temporal horns of the lateral 
Figure 2

Neuropathological examination of case 1 . (A) Topography of demyelinated areas. (B) $20 \mu \mathrm{m}$ thick celloidin embedded bihemispheric section through the red nucleus (Loyez stain for myelin) showing enlarged ventricles and severely atrophic corpus callosum. Demyelinated areas are present on both sides of the corpus callosum. (C) Plaque seen on a $7 \mu m$ thick paraffin embedded section stained by Bodian's protargol method associated with Luxol fast blue for myelin (originally $\times 300$ ).

Note the demyelinated area (pale, on the right).
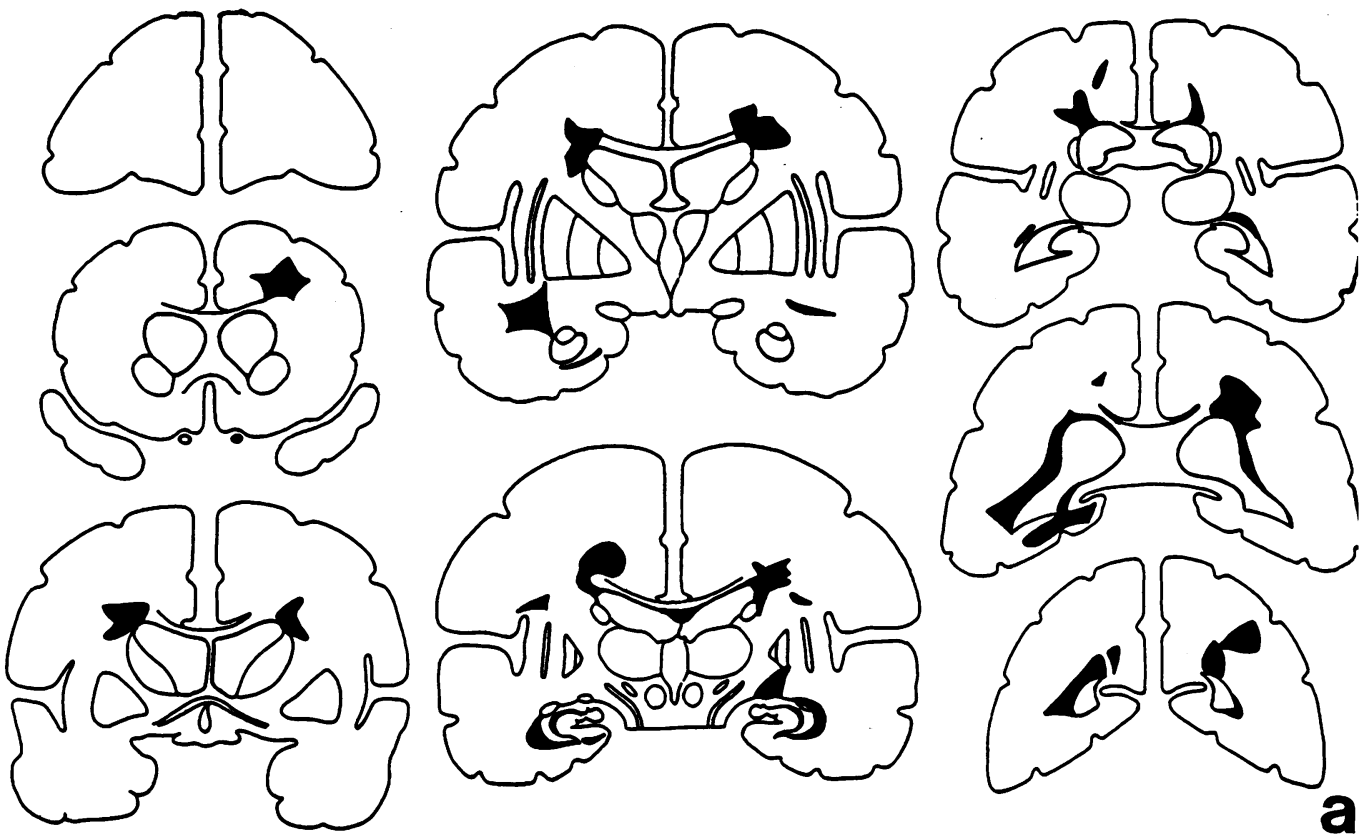

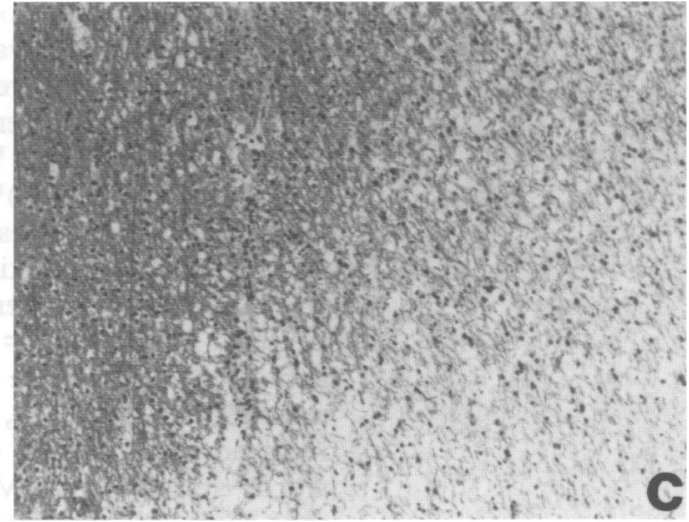

CASE 2

A 24-year-old right handed woman was admitted to hospital in July 1991 with a behavioural disturbance. She was born in Spain and had lived in France since her birth. Her parents and two sisters were in good health. Her mother had had a mild depressive episode. Her birth and infancy were unremarkable. She achieved the appropriate grades at school and was considered a serious and good pupil. At the age of 8 , her parents noted that her behaviour had rapidly changed. She became less interested in going to school and she became aggressive. She left school when she was 12 years old because of her inability to keep up with school life. She reported mystic hallucinations. She was seeing God, Jesus Christ, and the Virgin Mary. She thought that this was the holy sign that she could cure people, and after a visit to a magic healer, she convinced her family of her magic skills. She was also seeing devils that frightened her, but she accepted these unpleasant hallucinations as being part of her divine destiny. She had no other types of hallucinations, especially auditory. At the time of her admission to hospital, she was apragmatic, her mood was depressive, and she was reticent to talk about her visions.

Neurological and general examinations 



Figure 3 MRI examination of brain of case 2. A, B, and C are T2-weighted transverse sections of the cerebral hemispheres.

gave normal results. Optic fundi and retinae were unremarkable. There was no gait disorder. The cranial nerves, and cerebellar, sensory, and motor functions were normal. There was no visceromegaly. Neuropsychological examination was performed in March 1991. It showed severe cognitive dysfunction. Intellectual impairment was noted on the revised form of the Wechsler adult intelligence scale (WAIS-R) ${ }^{14}$ with a final IQ of 60 . Visuospatial processes seemed to be more affected than linguistic processes and there was a 17 point difference between the verbal subtests (verbal $I Q=65$ ) and performance subtests (performance IQ $=48$ ). Naming was normal (80 pictures), although fluency was reduced (12 names of animals and three words starting with $M$ in one minute), and the copy of the Rey figure ${ }^{14}$ was mildly impaired. In BEM 144, free recall was poor for verbal (a story) and visual (a geometric figure) information, and there was no incremental learning: on a series of 12 words, the learning curve was $3,4,4$ (which corresponds

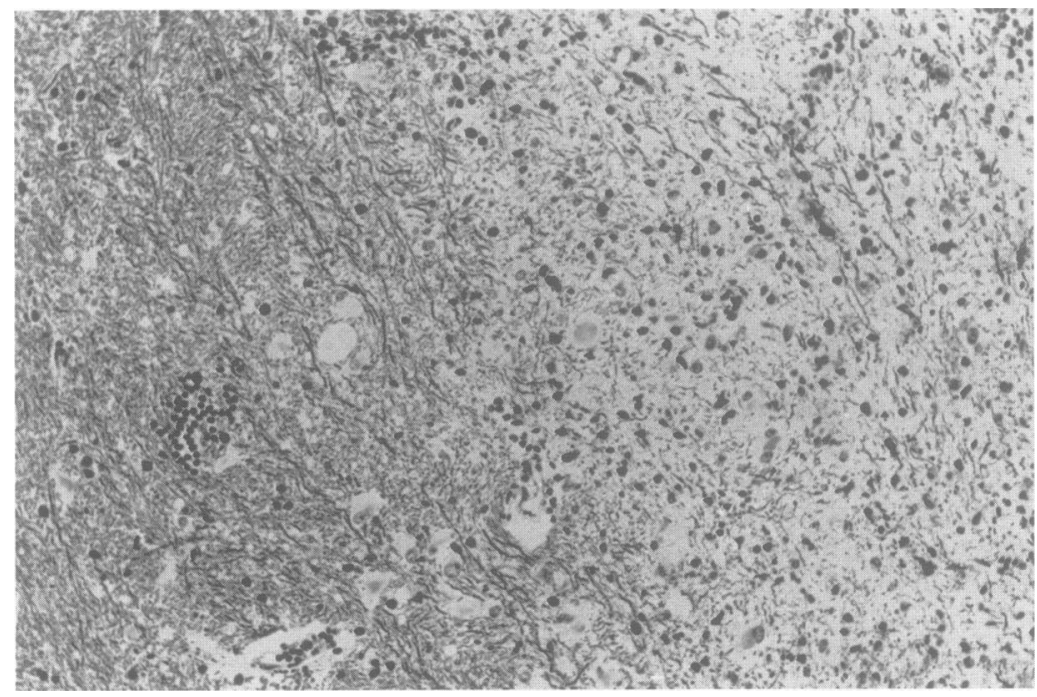

Figure 4 Microscopical examination biopsy specimen from case 2. Biopsy of the large left frontal plaque was performed under stereotaxis. Staining was by Bodian's protargol method associated with Luxol fast blue for myelin and Hemalun stain (originally $\times 150$ ). It shows a typical multiple sclerosis plaque with complete demyelination and preservation of axons in the demyelinated area. to the digit span). ${ }^{14}$ Apart from this severe intellectual and memory dysfunction, there was also a loss of educational knowledge: in arithmetric calculation, only simple additions could be achieved. The digits were correctly aligned but she was unable to perform the computation.

Laboratory tests were normal. There was no inflammatory syndrome. There was no sign either of an autoimmune disorder or of sarcoidosis. Syphilis and HIV serologies were negative. The CSF was normal. Visual, auditory, and somatosensory evoked potentials were normal. The EEG disclosed cerebral dysrhythmia, with intermittent $\delta$-waves predominating on the left hemisphere. There were no epileptic figures. The EMG was normal. The blood concentrations of long chain fatty acids and arylsulfatase activity were normal. A cerebral MRI was performed in April 1989 with T1-weighted sagittal sections and T2-weighted transverse sections. On T2weighted stquences, areas of high signal were present in the periventricular white matter. A large plaque in the left frontal lobe was located close to the left frontal ventricular horn (fig 3A). This large plaque appeared as an area of low signal in the frontal white matter on T1-weighted sagittal sections, and as a high signal area on T2-weighted sections. There were also small lesions scattered throughout the right fontal lobe and in the white matter close to the occipital horns of the ventricules (fig 3B), and a larger lesion in the left temporal lobe (fig 3C). The brainstem was not affected and the corpus callosum showed no atrophy. An MRI of the spinal cord, performed in May 1989, was normal. In June 1989, a cerebral biopsy of the left frontal lobe was performed under stereotactical conditions. Microscopical examination of this frontal biopsy showed an active plaque of multiple sclerosis in the white matter (fig 4). The lesion was well demarcated and surrounded by a dense reactive gliosis. Myelin loss was predominant and axons were spared. Within the demyelinated area, blood vessels were cuffed by lymphocytes and macrophages. On a cerebral MRI examination performed in October 1991, the 
number of periventricular high signal lesions had slightly increased. No abnormality was seen in the brainstem, cerebellar cortex or spinal cord.

During her stay in hospital, the patient was considered to be primarily depressed and several antidepressant and neuroleptic drugs were given. Her depressive mood and apragmatic behaviour improved, but the hallucinations persisted. She left the hospital in September 1991 for a long term care unit. In February 1992, she complained of paresthesiae affecting both the right hemiface and upper limb which lasted several weeks. A cerebral MRI examination performed in May 1992 disclosed a new T2-high signal lesion in the left upper brainstem.

A second neuropsychological examination was performed in May 1992. The patient was willing to cooperate. The IQ remained stable at 60 on the WAIS-R. ${ }^{14}$ In BEM144, her score was at $2.5 \mathrm{SD}$ below the mean of a group of the same age and cultural level. ${ }^{14}$ In the Wisconsin card sorting test, four out of six criteria were elaborated. ${ }^{14}$ Sixteen out of 48 errors were consistent with a difficulty in maintaining a strategy. In the Stroop test, ${ }^{14}$ al scores were low (words, 32; colours, 30; colour-word, 32 in T notes). Tests for verbal fluency remained weak although naming was correct. By comparison with the preceding examination, the copy of the Rey figure ${ }^{14}$ had deteriorated considerably: the reproduction was totally disorganised, the external configuration being broken, and several details were repeated; details were recognisable, however, and graphism was not altered.

\section{Discussion}

Two female patients presented with a progressive dementia and had histologically confirmed multiple sclerosis. The predominant neurological abnormality was a dementia, and neuroimaging studies suggested changes in the white matter. In previously described patients with multiple sclerosis in whom dementia was predominant, ${ }^{12}$ other signs of neurological dysfunction were present supporting the diagnosis of multiple sclerosis, or the diagnosis of laboratory supported multiple sclerosis ${ }^{15}$ could be made on the basis of lymphocytic hypercellularity or hyper- $\gamma$-globulinaemia in the CSF. In our two cases the diagnosis finally relied on histological examination (necropsy and cerebral biopsy). Silent plaques have been described (five in 2450 in the series of Gilbert and Sadler). ${ }^{16}$ Therefore, a comparative analysis was performed to try to establish a correlation between the location of the plaques and the cognitive abnormalities with reference to the already published cases.

In case 1 , the onset was in adulthood and a progressive course over 13 years finally led to death. Several authors have pointed out the resemblance between dementia in multiple sclerosis and the socalled "subcortical dementia". ${ }^{17-20}$ Case 1 showed characteristics of subcortical dementia: learning disability, apragmatism, reduction in verbal fluency, and mood disorders. The loss of memory was reminiscent of an alcoholic Korsakoff syndrome. Initial presentation with a Korsakoff syndrome in multiple sclerosis has already been noted. ${ }^{21}$ By contrast with our case, there was brainstem involvement. ${ }^{21}$ In common with the case of Vighetto et $a l_{,}{ }^{21}$ we found, on MRI evidence, demyelination in the white matter of the hippocampus, which could contribute to the amnestic syndrome. Atrophy of the corpus callosum and ventricular enlargement have also been reported to correlate with dementia in multiple sclerosis. ${ }^{22} 23$

Postmortem examination disclosed plaques exclusively located to the hemispheric white matter. The right optic nerve was also demyelinated. In the 70 necropsies of multiple sclerosis studied by Ikuta and Zimmerman, ${ }^{24}$ plaques were restricted to the supratentorial white matter in $7 \%$ and to the supratentorial white matter and the optic nerve in $14 \%$ of patients. ${ }^{24}$

The cerebral lesions responsible for dementia in case 1 were analysed in more detail than in other published necropsy cases. ${ }^{25}$ The cognitive impairment could not be explained by lesions localised in the cortex: there were no plaques in the grey matter, ${ }^{26}$ and no associated lesions, such as amyloid angiopathy. ${ }^{27}$ Lesions were localised in the brain white matter and axons were disrupted by necrotic plaques located on both sides of the corpus callosum. Plaques were found in the limbic system (the alveus, the fornix, and the cingulum), which might be correlated to the short term memory disturbance. In both hemispheres, plaques disrupted the cingulum, the superior frontooccipital, the superior longitudinal, and the uncinate fasciculi, which connect the frontal cortex to the temporal, parietal, and occipital cortices. ${ }^{28-30}$ Lesions of associative fibres might result in a disconnection syndrome of the long associative bundles. ${ }^{28}$ The neural network involved in attention that originates in the posterior parietal cortex follows those pathways and ends in the frontal cortex. ${ }^{31} \mathrm{~A}$ disruption of this pathway may have contributed to the attentional disturbance found in the first patient.

In the second case, the onset was more difficult to establish with certainty. Behavioural changes began at the end of the first decade, but cognitive dysfunction and MRI abnormalities were only documented at the end of the second decade. Cases of multiple sclerosis starting before the age of 10 are rare (less than $1 \%$ of all multiple sclerosis cases). ${ }^{32}$ The two neuropsychological examinations showed a stable cognitive deficit concerning intellectual and mnesic efficiency. The quality of basic learning (reading and dictation) was interpreted in favour of the acquired origin of the cognitive abnormalities (arithmetic calculation). In the verbal tests, answers were poor, but always pertinent and realistic. The score in the subtest of the similarities at the WAIS-R was the best, showing that there were no major problems in conceptual reasoning. The alteration of the copy of the 
Rey figure could not be attributed to delusions that were already present during the first examination. Taken together, the selective loss of educational knowledge, the alteration of the Rey figure, the major slowing of the intellectual processes, the difficulty in maintaining a strategy, and the limitation in verbal fluency were interpreted as signs of an organic origin for the cognitive deficits. Therefore, multiple sclerosis was considered to be the cause of the dementia, rather than schizophrenia. The possibility remains, however, that both multiple sclerosis and a concommitant schizophrenia might explain the demential syndrome in case 2 . The role of multiple sclerosis in the psychotic syndrome is more disputable, and a schizophrenia cannot be dismissed. Hallucinations were, however, unimodal, which is an argument to support the organic origin of the psychotic syndrome.

MRI showed that lesions were predominantly in the left frontal lobe (a large plaque), but there was also evidence of white matter changes in the left temporal lobe and in the occipital lobes.

Psychotic symptoms are not prominent in multiple sclerosis and hallucinations are rare. Both acute and remitting, or chronic psychosis have been reported in multiple sclerosis. ${ }^{33-38}$ As an argument to support the role of multiple sclerosis lesions in psychotic symptoms, the distribution of the lesions was analysed. 3539 From these studies it was suggested that the temporal lobe might be preferentially involved without evidence of laterality. ${ }^{35} 39$ One case with a psychotic syndrome characterised by hebephrenia and a paranoid state showed large plaques in the white matter of both frontal lobes. ${ }^{37}$ In accord with these findings, the more severely affected regions in case 2 shown on MRI included both the left frontal and temporal lobes.

Therapeutic approaches to dementia in multiple sclerosis are disappointing. Because of the absence of attacks, there was no rational basis for steroid treatment in our cases. In the first case, a trial with steroid treatment was inefficient. This is consistent with the findings of Young et $a l^{12}$ and Franklin et al. ${ }^{2}$ For example, in the cases 1 and 4 of Young et $a l,{ }^{12}$ the authors noted a clinical amelioration of the neurological symptoms, but no effect on the dementia.

Dementia in multiple sclerosis is rare, but multiple sclerosis should be considered as a possible cause of dementia. MRI and neuropathological examination, when possible, might help to correlate the site of the plaques with the cognitive or psychiatric dysfunction. ${ }^{4041}$

We thank Dr H Déchy (Versailles, France) for referring patient 1, and for allowing us a close follow up of case 1 . We thank Pr P Brunet (Hôpital de la Salpêtrière, Paris) for calling patient 1 to our attention and for helpful discussions. We thank Pr Chodkiewicz (Hôpital Sainte Anne, Paris) for performing the cerebral biopsy of patient 2 . We acknowledge the financial support of the ARSEP. We thank Dr Alan Thompson (London, United Kingdom) for English revision.
1 Charcot JM. Lectures on the diseases of the nervous system. London: New Sydenham Society, 1877.

2 Franklin GM, Nelson LM, Filley GM, Heaton RK Cognitive loss in multiple sclerosis: case reports and review of the literature. Arch Neurol 1989;46:162-7.

3 Ron MA, Feinstein A. Multiple sclerosis and the mind. f Neurol Neurosurg Psychiatry 1992;55:1-3.

4 Peyser JM, Rao SM, LaRocca NG, Kaplan E. Guidelines for neuropsychological research in multiple sclerosis. Arch Neurol 1990;47:94-7.

5 Rao SM, Leo GJ, Bernardin L, Unverzagt F. Cognitive dysfunction in multiple sclerosis. I: Frequency, patterns and prediction. Neurology 1991;41:685-91.

6 Peyser JM, Edwards KR, Poser CM, Filskov SB. Cognitive function in patients with multiple sclerosis. Arch Neurol 1980;37:577-9.

7 Grant I, McDonald WI, Trimble MR, Smith E, Reed R. Deficient learning and memory in early and middle phases of multiple sclerosis. $f$ Neurol Neurosurg Psychiatry 1984;47:250-5.

8 Rao SM, Hammeke TA, McQuillen MP, Khatri BO, Lloyd D. Memory disturbance in chronic progressive multiple sclerosis. Arch Neurol 1984;41:625-63.

9 Lyon-Caen $O$, Jouvent $R$, Hauser $S$, et al. Cognitive function in recent-onset demyelinating diseases. Arch Neuro 1986;43:1138-41.

10 Rao SM, Leo GJ, Ellington L, Nauertz T, Bernardin L Unverzagt F. Cognitive dysfunction in multiple sclerosis. II: Impact on employment and social functioning. Neurology 1991;41:692-6.

11 Bergin JD. Rapidly progressing dementia in disseminated sclerosis. F Neural Neurosurg Psychiatry 1957;20:285-92.

12 Young AC, Saunders J, Ponsford JR. Mental change as an early feature of multiple sclerosis. I Neurol Neurosur Psychiatry 1979;39:1008-13.

13 Binois R, Pichot P. Paris: Test de vocabulaire. Centre de Psychologie Appliquée, 1958.

14 Weintraub S, Mesulam MM. Mental state assessment of young and elderly adults in behavioral neurology. In: young and elderly adults in behavioral neurology. In: Philadelphia: Davies, 1988:71-123.

15 Poser CM, Paty DW, Scheinberg L, et al. New diagnostic criteria for multiple sclerosis: guidelines for research protocols. Ann Neurol 1983;13:227-31.

16 Gilbert JJ, Sadler M. Unsuspected multiple sclerosis. Arch Neurol 1983;40:533-6.

17 Filley CM, Heaton RK, Nelson LM, Burcks JS, Franklin GM. A comparison of dementia in Alzheimer's disease and multiple sclerosis. Arch Neurol 1989;46:157-61.

18 Albert ML, Feldman R, Willis AL. The subcortica dementia of supranuclear palsy. $f$ Neurol Neurosurg Psychiatry 1974;37:121-30.

19 Cummings JL. Subcortical dementia: neuropsychology, neuropsychiatry and pathophysiology. $B r \mathcal{F}$ Psychiatry 1986;149:682-97.

20 Rao SM. Neuropsychology of multiple sclerosis: a critical review. F Clin Exp Neuropsychol 1986;8:503-42.

21 Vighetto A, Charles N, Salzmann M, Confavreux C, Aimard G. Korsakoff's syndrome as the initial presentation of multiple sclerosis. I Neurol 1991;238:351-4.

22 Barnard RO, Triggs M. Corpus callosum in multiple sclerosis. I Neurol Neurosurg Psychiatry 1974;37:1259-64.

23 Huber SJ, Paulson GW, Shuttleworth EC, et al. Magnetic resonance imaging correlates of dementia in multiple sclerosis. Arch Neurol 1987;44:732-6.

24 Ikuta F, Zimmerman HM. Distribution of plaques in seventy autopsy cases of multiple sclerosis in the United States, US-Japan Conference on Multiple Sclerosis. Neurology 1976;26:26-8.

25 Brownell B, Hughes JT. The distribution of plaques in the cerebrum in multiple sclerosis. I Neurol Neurosurg Psychiatry 1962;25:315-20.

26 Lumsden CE. Neuropathology of multiple sclerosis. In: Vinken PJ, Bruyn GW, eds. Handbook of clinical In: Vinken PJ, Bruyn GW, eds. Handbook of clinical

27 Heffner RR, Porro RS, Olson ME, Earle KM A demyelinating disorder associated with cerebrovascular amyloid nating disorder associated with cerebrovasc

28 Geschwind N. Disconnexion syndromes in animals and man, part 1. Brain 1965;88:237-94.

29 Dejerine J. Anatomie des centres nerveux. Vol. 1. Paris: Ruef, 1895:761-5.

30 Crosby EC, Humphrey T, Lauer EW. Correlative anatomy of the nervous system. New York: Macmillan, 1962: $402-9$.

31 Mesulam MM. Attention, confusional states, and neglect. In: Mesulam MM, ed. Principles of behavioral neurology. Philadelphia: Davis, 1988:116-25.

32 Kurtzke JF. Epidemiology of multiple sclerosis. In: Vinken PJ, Bruyn GW, Klawans HL, eds. Handbook of clinical

33 Minden SL, Schiffer RB. Affective disorders in multiple sclerosis: review and recommendations for clinical research. Arch Neurol 1990;47:98-104.

34 Matthews WB. Multiple sclerosis presenting with acute remitting psychiatric symptoms, f Neurol Neurosurg remitting psychiatric sympto

35 Honer WG, Hurwitz T, Li DKB, Palmer M, Paty DW. Temporal lobe involvement in multiple sclerosis patients with psychiatric disorders. Arch Neurol 1987; 44:187-90.

36 Neumann PE, Mehler MF, Horoupian DS, Merriam AE. Atypical psychosis with disseminated subpial demyelination. Arch Neurol 1988;45:634-6. 
37 Kohler J, Heilmeyer H, Volk B. Multiple sclerosis presenting as chronic atypical psychosis. I Neurol Neurosurg ing as chronic atypical

38 Felgenhauer $\mathrm{K}$. Psychiatric disorders in the encephalitic form of multiple sclerosis. $\Im$ Neurol 1990;237:11-8.

39 Feinstein A, Du Boulay G, Ron MA. Psychotic illness in multiple sclerosis: a clinical and magnetic resonance imaging study. Br f Psychiatry 1992;161:680-5.
40 Rao SM, Leo GJ, Haughton VM, St Aubin-Faubert P, Bernardin L. Correlation of magnetic resonance imaging with neuropsychological testing in multiple sclerosis. Neurology 1989;39:161-6.

41 Swirsky-Sacchetti T, Mitchell DR, Seward J, et al. Neuropsychological and structural brain lesions in multiple sclerosis: a regional analysis. Neurology 1992;42: 1291-5.
Robert Bentley Todd (1809-60) and locomotor ataxia

Dr Todd, who was by far the greatest clinical neurologist Great Britain has produced until the time of Hughlings fackson, was the first to begin the breaking up of the spinal diseases, at that time all classed as paraplegia, by his discovery of locomotor ataxy as a distinct disease.

\section{Fames Collier, \\ Harveian oration 1934}

I have elsewhere noted some of the remarkable accomplishments of Robert Bentley Todd (p.315), the Dublin born physician whose life's work was at King's College. Apart from his celebrated Cyclopaedia and his depictions of migraine, peripheral neuritis, and postepileptic paralysis, he provided an important discourse on locomotor ataxy (tabes dorsalis). Gowers observed, "The credit of the discovery of the disease belongs, if to anyone, unquestionably to Todd."

Gowers acknowledged the contributions of Stanley Romberg (1851), Russell Reynolds (1855), Sir William Gull (1856), and Duchenne (1858) who coined the name "locomotor ataxy". Todd wrote:

Two kinds of paralysis of motion may be noticed in the lower extremities, the one consisting simply in the impairment or loss of voluntary motion, the other distinguished by a diminution or total loss of the power co-ordinating movement. In the latter form, while considerable voluntary power remains, the patient finds great difficulty in walking and his gait is so tottering and uncertain that his centre of gravity is easily displaced.... In two examples of this variety of paralysis I ventured to predict disease of the posterior columns, the diagnosis being founded upon the views of their functions which I now advocate; and this was found to exist on a post-mortem inspection; and in looking through the accounts of recorded cases in which the posterior columns were the seat of the lesion, all seem to have commenced by evincing more or less disturbance of the locomotive powers, sensation being affected only when the morbid change of structure extended to and more or less involved the posterior roots of the spinal nerves."

Romberg's more descriptive account (see $\mathcal{f}$ Neurol Neurosurg Psychiatry 1993;56:51, Romberg's sign) came later:

... the sense of touch and muscular sense diminished, while the sensibility of the skin is unaltered in reference to temperature and painful impressions. ... The gait begins to be insecure.... The individual keeps his eyes on his feet to prevent his movements from becoming still more unsteady. If $h e$ is ordered to close his eyes while in the erect posture, he at once commences to totter and swing from side to side; the insecurity of his gait also exhibits itself more in the dark. . .

Although the occasional relation to syphilis had been noted previously, Fournier was the first (in 1876) to assert the wide extent of this relation, later confirmed by Gowers, ${ }^{1}$ and by Möbius: "Omnis tabes elue."3

JMS PEARCE
304 Beverley Road,
Anlaby,
Hull HU10 7BG

1 Gowers WR. A manual of diseases of the nervous system, 1st ed, vol 1. London: Churchill, 1886:287-9.

2 Todd RB. Cyclopaedia of anatomy and physiology, vol 3. London: Longman and Roberts, Longman, Brown, Green, 1847:721.

3 Möbius PJ. Ueber die Tabes, 1897. Cited by Wilson SAK. In: Neurology. London: Edward Arnold, 